Feruglio GA. La chiusura percutanea delle fistole arteriose coronariche congenite e iatrogene. G Ital Cardiol 1995;25:1381-7.

5 Uchida N, Baudet E, Roques X, Laborde N, Billes MA. Surgical experience of coronary artery-right ventricular fistula in a heart transplant recipient. Eur $¥$ Cardiothorac Surg 1995;9:106-8.

6 Shimabukuro $M$, Shinzato $T$, Yoshida $H$, Nagamine F, Takasu N, Koja K. Late complications in a traumatic coronary artery fistula; a report of a case requiring surgical repair after 8 years. Cardiology 1996;87:86-9.

7 Qureshi SA, Reidy JF, Bin Alwi M, Lim MK, Wong J, Tay J, et al. Use of interlocking detachable coils in embolization of coronary arteriovenous fistulas. $A m \mathcal{f}$ embolization of coronary

8 Perry SB, Rome J, Keane JF, Baim DS, Lock JE. Transcatheter closure of coronary artery fistulas. $\mathcal{F} \mathrm{Am}$ Coll Cardiol 1992;20:205-9.

\title{
Single coronary artery with infundibular pulmonary stenosis
}

Taku Yamamoto, Yoshizumi Habuchi, Junichiro Morikawa

Third Department of Internal Medicine, Kyoto Prefectural University of Medicine, KawaramachiHirokoji, Kamigyo-ku, Kyoto 602, Japan $T$ Yamamoto J Morikawa

Department of Laboratory Medicine Y Habuchi

Correspondence to: Dr Yamamoto. 28 May 1997 Accepted for publication

Single coronary artery is a rare congenital anomaly. ${ }^{1}$ Infundibular pulmonary stenosis (IPS) without ventricular septal defect or tetralogy of Fallot (isolated IPS) is also very rare. ${ }^{2}$ We report a case of single coronary artery with isolated IPS; to our knowledge, this is the first report of such a case.

\section{Case report}

A 57 year old asymptomatic man was referred to our hospital because of chest radiography and ECG abnormalities. Physical examination revealed a grade 4 harsh systolic ejection murmur heard best in the fourth intercostal space at the left sternal border. Chest radiography showed right atrial and ventricular enlargement with a cardiothoracic ratio of 0.55 . Pulmonary vascularity was normal. ECG showed right ventricular hypertrophy.

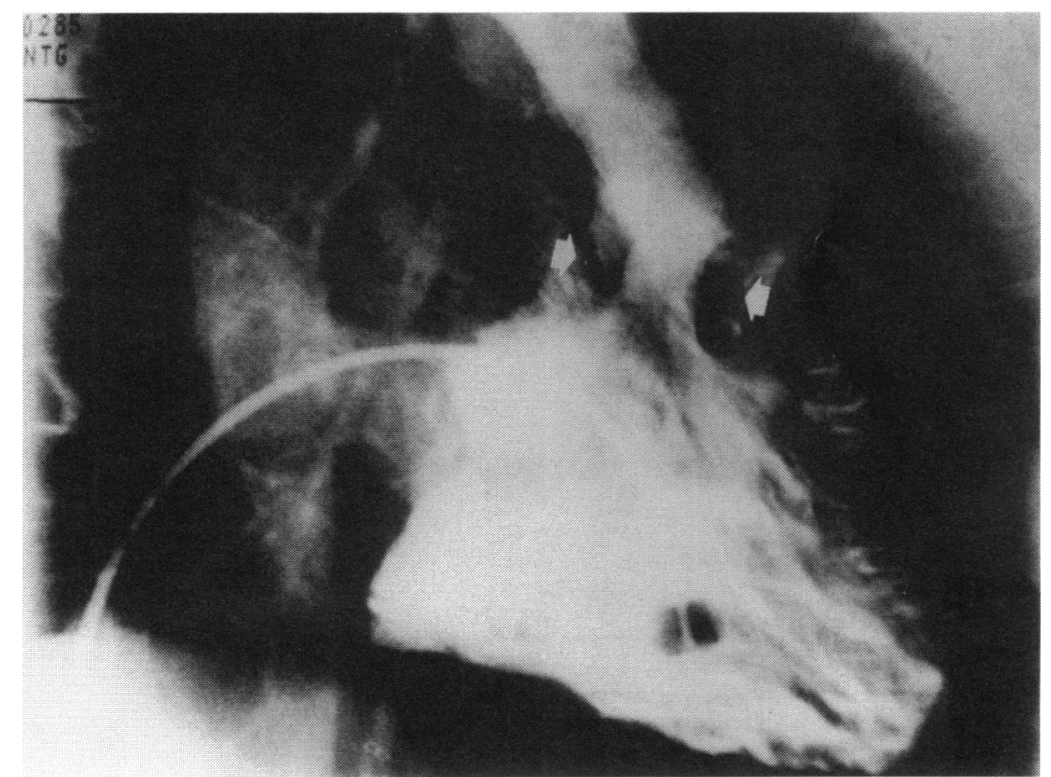

Figure 1 Right anterior oblique view of right ventricular angiography revealing infundibular pulmonary stenosis (arrows). Both the pulmonic valve and the ventricular septum were intact.
Echocardiography revealed a dilated right ventricular body and a protruding lesion at the proximal portion of the infundibulum. Cardiac catheterisation disclosed a peak systolic pressure gradient of $68 \mathrm{~mm} \mathrm{Hg}$ between the right ventricular body and the infundibulum. The right atrial and the pulmonary arterial pressures were normal. Oxygen sampling revealed no evidence of shunting. Right ventricular angiography revealed a prominent muscle band at the junction of the right ventricular body and the infundibulum (fig 1). Both the pulmonic valve and the ventricular septum were intact. Coronary artery angiography revealed a solitary left sided coronary ostium. An anomalous right coronary artery ran from the left anterior descending artery anteriorly to the root of the main pulmonary artery without stenosis (fig 2). It arose from the middle portion very close to the first septal perforating branch of the left anterior descending artery. These findings are compatible with isolated IPS associated with single coronary artery.

The patient underwent surgical resection of the anomalous muscle band and no vestige of ventricular septal defect was found at operation.

\section{Discussion}

In most cases of single left coronary artery, the right coronary artery arises from the main trunk, the proximal portion of the left anterior descending artery, or the left circumflex artery. ${ }^{3}$ Few reports have described cases of anomalous right coronary artery arising from the middle portion of the left anterior descending artery without other congenital anomalies. ${ }^{13}$ Single coronary artery is usually combined with various cardiac anomalies such as improper division of truncus arteriosus, transposition of great vessels, and tetralogy of Fallot. The present case was associated with isolated IPS, itself a rare anomaly. Most patients with IPS are diagnosed and surgically 

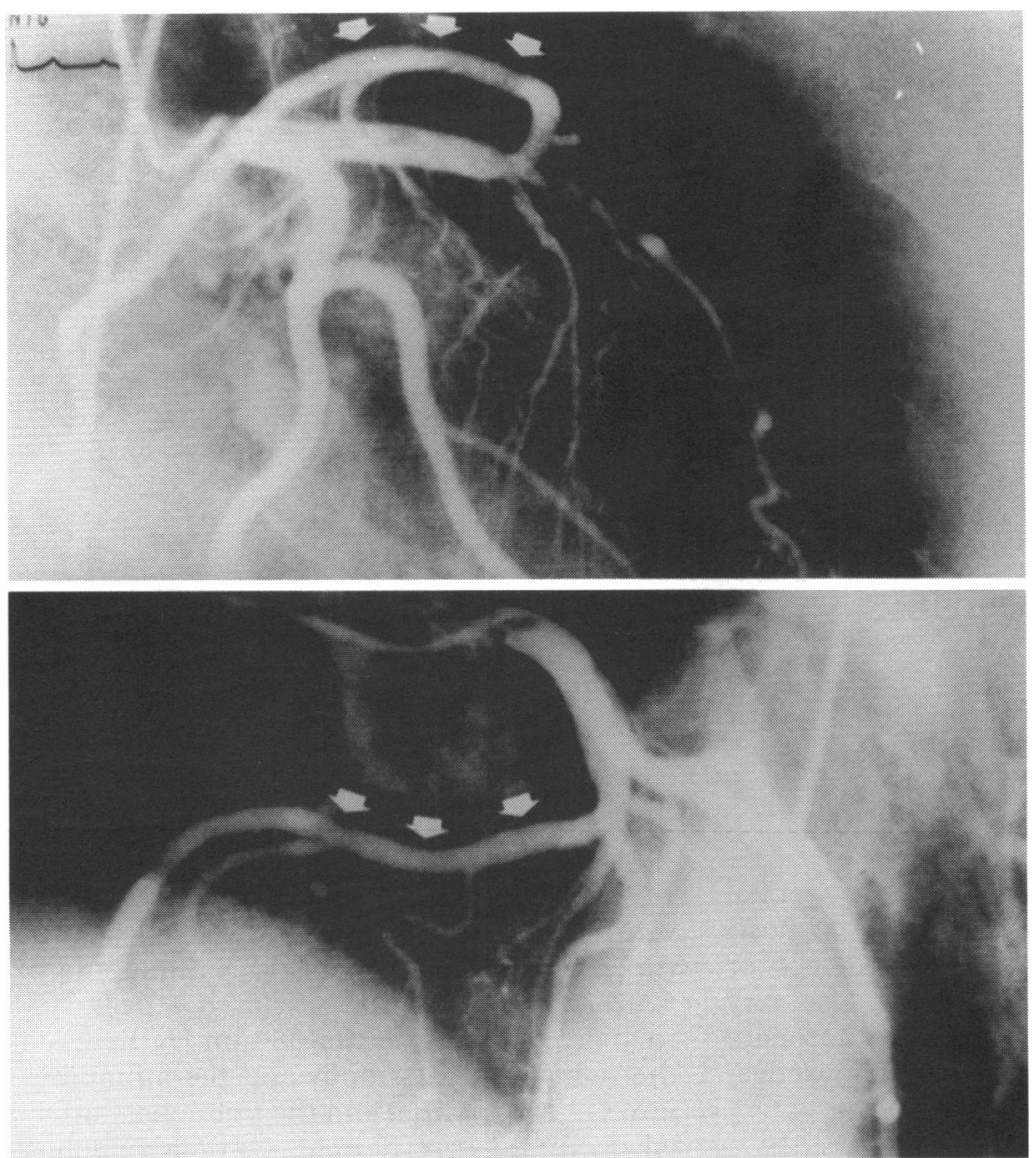

Figure 2 Right anterior oblique (upper panel) and left anterior oblique (lower panel) views of coronary artery angiography revealing an anomalous right coronary artery (arrows), which arose from the left anterior descending artery. treated in early infancy because other combined anomalies, such as ventricular septal defect or tetralogy of Fallot, produce a shunt. In this case, the patient had been asymptomatic and was first diagnosed in his late $50 \mathrm{~s}$ because no shunt was present and the stenosis was mild. No case of single coronary artery with isolated IPS has been reported.

From an embryological standpoint, a failure in sprouting of the primitive aortic sinus wall during the fifth to sixth intrauterine week results in single coronary artery. ${ }^{4}$ Insufficient absorption of the mesenchymal tissue in the right ventricle leads to anomalous muscle partition between the right ventricular body and the infundibulum. This absorption occurs at the same embryonic period as the sprouting of coronary arteries from the aortic sinus. ${ }^{5}$ This close timing between the development of coronary arteries and the right ventricle may explain the rare combination of single coronary artery and IPS in the present case.

1 Biffani G, Lioy E, Loschiavo P, Parma A. Single coronary artery, anomalous origin of the right coronary artery from 12:1326-9.

2 Zaret BL, Conti CR. Infundibular pulmonic stenosis with intact ventricular septum in the adult. Fohns Hopkins Med intact ventricular sept

3 Moreyra AE, Tannenbaum AK, Leeds $R$ A rare variant of single left coronary artery. Am Heart $\mathcal{f}$ 1993;125:524-6.

4 Larsen WJ. The coronary vessels develop from blood islands deep to the epicardium. In: Schmitt WR, Otway M, Bowman-Schulman E, eds. Human embryology. New York: Churchill Livingstone, 1993:191.

5 Watler DC, Wynter L. Cor triventriculare: infundibular stenosis with subdivision of the right ventricle. Br Hear $\mathcal{F}$ 1961;23:599-602. 